Teknokultura. Revista de Cultura Digital y Movimientos Sociales

ISSNe: $1549-2230$

http://dx.doi.org/10.5209/TEKN.70225

\title{
Antifeminismo y troleo de género en Twitter. Estudio de la subcultura trol a través de \#STOPfeminazis ${ }^{1}$
}

\author{
Alícia Villar-Aguilés²; Juan Pecourt Gracia ${ }^{3}$
}

Recibido: 18 de junio de 2020 / Aceptado: 13 de noviembre de 2020 Open peer reviews

\begin{abstract}
Resumen. En los últimos años, el auge del movimiento feminista, especialmente desde la convocatoria del 8M de 2018, se ha encontrado con resistencias importantes. En el ámbito digital, esta renovación del feminismo ha supuesto un aumento del activismo digital feminista y una mayor visibilidad de las mujeres. Sin embargo, también han surgido múltiples obstáculos que muestran el carácter androcéntrico y misógino de la cultura digital. Uno de los fenómenos asociado a la misoginia digital es el "troleo de género" (gendertrolling), propio de la subcultura troll. En este trabajo, analizaremos el troleo antifeminista en la plataforma Twitter, centrándonos en la etiqueta \#STOPfeminazis. A partir del análisis de contenidos, mediante la aplicación de categorías específicas, observamos cómo esta etiqueta utiliza métodos de la subcultura troll, relacionados con la remezcla y la resignificación, para llevar a cabo una ofensiva general contra el movimiento feminista.
\end{abstract}

Palabras clave: cultura digital; misoginia digital; redes sociales; violencia machista

\section{[en] Antifeminist and gendertrolling on Twitter: a study of the troll-subculture through \#STOPfeminazis}

\begin{abstract}
In recent years, the rise of the feminist movement, especially since $8 \mathrm{M}$ of 2018 , has been met with serious resistance. In the digital world, this renewal of feminism has led to an increase in feminist digital activism and greater visibility of women. However, multiple obstacles have also emerged that expose the androcentric and misogynistic nature of digital culture. One of the phenomena associated with digital misogyny is gendertrolling, typical of the troll subculture. In this paper, we analyse antifeminist trolling on the Twitter platform by focusing on the hashtag \#STOPfeminazis. Based on content analysis and the application of analytic categories, we observe how this hashtag uses the remixing and resignification methods of the troll subculture to carry out a general offensive against the feminist movement.
\end{abstract}

Keywords: digital culture; online misogyny; sexist violence; social networks

Sumario. 1. Introducción. 2. Internet y la subcultura troll. 3. Estudio de la subcultura troll a través de la etiqueta \#STOPfeminazis. 4. Discusión y conclusiones. 5. Referencias.

Cómo citar: Villar-Aguilés, A.; Pecourt Gracia, J. (2021). Antifeminismo y troleo de género en Twitter. Estudio de la subcultura trol a través de \#STOPfeminazis. Teknokultura. Revista de Cultura Digital y Movimientos Sociales, 18(1), 33-44.

\section{Introducción}

La ciberviolencia contra las mujeres es una corriente profunda de Internet relacionada con el androcentrismo que lo caracteriza desde sus orígenes. No se trata de violencias aleatorias o casuales, sino que tienen unas pautas específicas que han evolucionado a lo largo del tiempo, amoldándose a las diferentes etapas de Internet. Las características específicas de estas formas de violencia en red están muy condicionadas por la subcultura trol que opera en ciertos territorios digitales (Coleman, 2012). En términos generales, la cultura digital (a través de estructuras impersonales, pero también de individuos concretos) tiende a invisibilizar a las mujeres o desplazarlas hacia la periferia. Esto quiere decir que todas aquellas acciones orientadas a reivindicar una posición de más centralidad en la sociedad (como las que realiza históricamente el feminismo) han tenido una fuerte contestación en Internet. Es cierto que Internet ha favorecido el activismo feminista, pero también ha impuesto nuevas presiones y obstáculos sobre el movimiento.

\footnotetext{
Este artículo está vinculado al proyecto "Problemas públicos y controversias: diversidad y participación en la esfera mediática", del Programa Estatal de I+D+I orientada a los Retos de la Sociedad, convocatoria 2017 (REF CSO2017-82109-R).

2 Universitat de València (España)

E-mail: alicia.villar@uv.es

3 Universitat de València (España)

E-mail: juan.pecourt@uv.es
} 
En este contexto, el objetivo del presente trabajo es analizar el hashtag \#STOPfeminazis en la plataforma Twitter como un caso específico de troleo antifeminista en Internet. Surgido como reacción al auge del movimiento feminista en los últimos años, especialmente a partir de la convocatoria del 8M de 2018, \#STOPfeminazis es un ejemplo de la lógica androcéntrica del Internet más reciente, dominado por redes sociales como Facebook, Twitter o Instagram, y caracterizado por la circulación de contenidos virales que muchas veces adquieren el formato de memes. De este modo, los micromensajes y memes de \#STOPfeminazis refuerzan la resistencia simbólica de ciertos sectores sociales ante el avance del feminismo. Esta resistencia tiene, en muchas ocasiones, un carácter subcultural, al basarse en la reformulación o "bricolaje" (Hebdige, 1979) de lemas y símbolos procedentes feminismo.

En las siguientes páginas, observaremos cómo se realiza este ejercicio de manipulación simbólica atendiendo a las diferentes dimensiones que adquiere el troleo contra el feminismo. En primer lugar, abordaremos las características básicas de la subcultura troll en el entorno digital. Seguiremos, en segundo lugar, con el androcentrismo y la misoginia que suele caracterizar a esta subcultura, y cómo se materializa en formas específicas de gendertrolling. En tercer lugar, explicaremos la metodología empleada para el análisis del caso específico de \#STOPfeminazis. En cuarto lugar, analizaremos las categorías fundamentales que enmarcan el gendertrolling de \#STOPfeminazis. Y finalmente incluimos unas conclusiones generales sobre el análisis realizado.

\section{Internet y la subcultura trol}

Podría decirse que el desarrollo de Internet y las redes sociales ha revivido el sueño de la esfera pública apuntado por Habermas (1981), un espacio dedicado a la discusión racional, liberado de los poderes sociales y jerarquías oficiales existentes en el mundo offline. Son bien conocidas las apuestas de Benkler (2006) y Shirky (2008), entre otros muchos, por una esfera pública digital democrática y mayoritaria, adaptada a los intereses de individuos y comunidades, ajenos a las distorsiones y censuras de las instituciones tradicionales, ya sean partidos políticos, medios de comunicación de masas o agencias del Estado. Sin embargo, dejando de lado los beneficios innegables de este medio, Internet también muestra un lado oscuro que reproduce, aunque de forma refractada, las jerarquías y diferenciaciones sociales que encontramos en el mundo real (Levmore y Nussbaum, 2010).

En el ámbito de la discusión pública, uno de los elementos más distorsionantes es la aparición de los trolls y su obstaculización (siguiendo diferentes métodos y pautas culturales claramente establecidas) del discurso racional en la esfera pública digital que preveían los defensores más optimistas de la web 2.0. y las redes sociales (Phillips, 2015; Nagle, 2017). Los trolls realizan intervenciones ofensivas y confusas que interrumpen las formas civilizadas de comunicación online (Di Franco,
2020). Detrás de estos comportamientos aparentemente caóticos y aleatorios se esconden unas pautas culturales muy estables que hunden sus orígenes tanto en la cultura hegemónica como en la cultura específica de Internet, en los códigos y comportamientos que definen las acciones digitales (Phillips, 2015). De hecho, en el contexto digital, estas autoras y autores alertan de la existencia de una subcultura troll con una identidad, unas pautas de comportamiento, unas normas y valores, claramente establecidos. Las conductas troll han existido a lo largo de la historia de Internet, sólo hay que observar las campañas de acoso en los años noventa en American Online (Goldman, 2017). Lo nuevo es la creciente codificación de estos comportamientos anti-normativos y ofensivos, como puede observarse en la evolución de las acciones troll de Anonymous (Coleman, 2016).

Según Coleman (2012), un momento decisivo de este fenómeno se produce con la aparición de la plataforma digital 4chan (Coleman, 2012). Lanzada en el año 2003, 4chan es una plataforma de intercambio de imágenes y creación de memes entre usuarios anónimos (Stryker, 2014). Estas imágenes, modificadas mediante la resignificación y el remix (Lessig, 2012), dieron lugar a un canon cultural específico, a un conocimiento cultural esotérico que sólo podían apreciar los insiders y los iniciados (Shifman, 2014). Dentro de 4chan, el canal /b/ es el espacio donde se producen los elementos más disruptivos de la cultura 4chan y la emergente subcultura trol (Stryker, 2011). Son imágenes que cuestionan cualquier noción de lo políticamente correcto y que entran directamente en el territorio del racismo, la misoginia y el desprecio por los valores de la sociedad democrática hegemónica (Milner, 2014; Pecourt, 2015). Durante años, 4chan se ha convertido en una factoría de memes muy influyente, difundiendo en la esfera pública desde los LOLcats hasta el Pedobear. Otros sitios de Internet, como Encyclopedia Dramatica o Something Awful, complementarán a 4chan en esta etapa inicial de constitución de la subcultura trol. Dependiendo del momento histórico, estas acciones pueden seguir orientaciones políticas progresistas o posiciones claramente reaccionarias (Heikkilä, 2017).

Los trolls tienen una identidad específica y la adaptan a las diferentes plataformas digitales desde las que actúan. Esta identidad suele basarse en conocimientos subculturales profundos y un manejo sofisticado de las herramientas tecnológicas (Bardeau y Danet, 2011). Mediante la técnica del "bricolaje" (Hebdige, 1979) transforman y subvierten los símbolos hegemónicos de la sociedad, dotándolos de un poder burlesco, insultante y subversivo. Como actores presentes en el ámbito de la discusión pública, sus acciones se encuentran en las antípodas de la discusión racional preconizada por Habermas; al contrario, están guiados por una energía emocional denominada LULZ (acrónimo de laughing out loud), que implica una disociación clara entre las acciones individuales y sus implicaciones emocionales y psicológicas en los demás (Sandoval, 2013; Milner, 2014). Los defensores de esta subcultura consideran que el acoso, la burla y el desprecio se sitúan en un plano igualitario (equal opportunity laugher), es decir, se trata 
de un ámbito totalmente abierto donde todo el mundo puede participar (como acosador o como víctima). Pero lo cierto es que las campañas trol suelen dirigirse casi siempre hacia los colectivos con menos poder e influencia en la sociedad, y de forma destacada hacia las mujeres (Phillips, 2015; Lumsden y Morgan, 2017).

Uno de los principios distintivos de la subcultura troll es el anonimato, que se concreta en diversas formas (Coleman, 2016). Por ejemplo, los participantes de la red social 4chan son anónimos, pero otros espacios no presentan formas de anonimización tan tajantes. En un mundo caracterizado por la exaltación del yo y la autopromoción (Marwick, 2013), los trolls suelen recurrir al anonimato o, al menos, esconder parcialmente su identidad con pseudónimos. Este anonimato tiene explicaciones prácticas evidentes, como evitar las sanciones que pueden tener los actos subversivos en la red. Muchas veces los trolls atacan a personas poderosas, y no quieren ser rastreados ni perseguidos; otras veces se divierten acosando a personas débiles e indefensas, y aspiran a que sus comportamientos queden impunes. Pero también tiene una explicación más profunda: en sus orígenes (sin duda, este es el caso de 4chan), la subcultura troll es una reacción a la comercialización y democratización de Internet. El anonimato de los trolls es una forma de protesta contra la masificación, y un rechazo explícito de la cultura digital de Facebook y otros gigantes informáticos.

\subsection{Subcultura troll, androcentrismo y gendertrolling}

Bourdieu (2007) explica el androcentrismo de acuerdo con un sistema de oposiciones que define, no solamente la relación entre los sexos, sino también una cosmovisión de la realidad que está sexualizada. Para el sociólogo francés, la distinción entre lo masculino y femenino se relaciona con otras oposiciones que organizan simbólicamente la realidad social como arriba/abajo, duro/ blando, seco/húmedo, racional/emocional o abierto/cerrado. Estos sistemas de clasificación posicionan de forma diferenciada a hombres y mujeres en la sociedad, y más concretamente tienden a expulsar a las mujeres del espacio público para recluirlas en el ámbito del hogar y la intimidad (Fraser, 1992). Este sistema de oposiciones, y el consecuente relegamiento de las mujeres del espacio público, se reproduce en el espacio público digital (Ging y Siapera, 2018, 2019), donde circulan discursos y actúan individuos que tienden a proporcionar una mirada masculina de la acción digital, una mirada que expulsa a aquellas mujeres que no encajan o desafían los cánones culturales y los modos clasificatorios impuestos por el modelo dominante.

A este respecto, un elemento definitorio de la subcultura troll es su androcentrismo y misoginia (Nussbaum, 2010). Desde sus orígenes, la cultura digital ha sido definida en términos masculinos, un hecho que tiende a desplazar a las mujeres (Hafner y Lyon, 1996). Así, en las crónicas de la formación de las subculturas tecnológicas de los años sesenta, se alude a colectivos masculinos, que reproducen, aunque adaptándolo a las nuevas condiciones digitales, el androcentrismo de la sociedad dominante (Levy, [1984] 2010; Hafner y Lyon, 1996). Curiosamente, estos autores, al definir las características fundamentales de las primeras comunidades hackers, la presentan como una forma simultánea de masculinidad hegemónica y masculinidad fracasada (Kendall, 2002). Masculinidad hegemónica porque incide en propiedades comúnmente asignadas a los varones, como conceder más importancia a las cosas que a las relaciones, la comprensión del ciberespacio como un espacio de conquista, o la interiorización del comportamiento digital basado en la rivalidad y competencia permanente. Y masculinidad fracasada porque presenta a los tecnólogos como seres incompletos (de hecho, define un estilo de vida geek que se sitúa al margen de la sociedad hegemónica) (Gere, 2008), como individuos incapaces de integrarse en la sociedad oficial y, por supuesto, de relacionarse con las mujeres. Esta combinación de masculinidad dominante y fracasada conlleva una cierta construcción del geek o genio informático dominante en el mundo hacker hasta la actualidad. La tensión entre masculinidad dominante y fracasada condiciona su interacción problemática con las mujeres, y es un fermento de misoginia (Ging y Siapera, 2018).

Dentro de la esfera pública, el androcentrismo digital y la subcultura trol promueven un estilo confrontacional de participación y de debate público (Phillips, 2015). Esta lógica antagónica no es casual, se despliega en una sociedad caracterizada, en muchos aspectos, de formas más o menos disimulada, por la prevalencia del combate discursivo confrontacional. Sólo hay que observar las dinámicas propias de los debates políticos y las tertulias que se transmiten desde la televisión (Jacobs y Townsley, 2011; Wessler, 2018). El debate se convierte en un combate mediatizado donde el objetivo principal es demostrar la debilidad del rival, y a ser posible humillarlo. En otras palabras, y desde la perspectiva androcéntrica, convertir al "otro" en "otro femenino", demostrar la fortaleza del fuerte frente al débil. Esta concepción del debate público establece una clara distinción entre ganadores y perdedores, asignando cualidades masculinas a los primeros (agresividad, asertividad, racionalidad) y femeninas a los segundos (mansedumbre, inseguridad, emotividad) (Bourdieu, 2007).

En cierta manera, los trolls reciclan y adaptan corrientes profundas de la cultura occidental al contexto digital. De hecho, la Encyclopedia Dramatica, referente trol, identifica a Sócrates como uno de los fundadores de esta subcultura, concretamente lo presenta como "un famoso trol IRL de la Grecia pre-Internet" (Swallow y Hall, 2020). IRL es una expresión de la cultura de Internet para referirse a la vida del mundo real, fuera de los escenarios virtuales de Internet (IRL, In Real Life). Según Philips (2015) también asumen el estilo confrontacional del pensador alemán Schopenhauer en El arte del insulto (2011), donde describe las tácticas dialécticas para imponerse al contrincante, y que constituye un verdadero manual del troleo contemporáneo. Según Schopenhauer (2011), el objetivo principal de cualquier argumentación es ganarla, más allá de los argumentos aducidos. Podría decirse que Schopenhauer hackea el racionalismo ilustrado. Esto implica desnaturalizar, o 
convertir en parodia, los argumentos del otro. Esta provocación emocional del contrario se realizará mediante manipulaciones lingüísticas que el contrario considere inaceptables, como relacionar las propuestas feministas con el nazismo.

Los postulados de la Encyclopedia Dramatica han eclosionado en los entornos digitales del siglo XXI. Esta difusión se debe a las características específicas de Internet, a las decisiones tomadas en el diseño del código informático. Desde los estudios críticos de datos (Lanier, 2011; Boyd y Crawford, 2012, Milan y Gutiérrez, 2018), se han lanzado duras críticas contra la configuración del Internet comercial. Según esta perspectiva, el código no es neutro ni aséptico, y según el tipo de diseño que se adopte se favorecerán un tipo de interacción sobre otra, se abrirán determinadas posibilidades y se cerrarán otras. Internet, en su constitución actual, está pensado para interacciones de carácter conflictivo y también tiende a transformar a los individuos en objetos. Este proceso de cosificación de las relaciones humanas, y más concretamente de disociación de las acciones individuales de las implicaciones emocionales que éstas tienen en terceros, forma parte de la estructura básica de la red. Determina también una concepción androcéntrica, entendida como un espacio de imposición y luchas de poder, que impone la mirada masculina dominante de la realidad (Jane, 2017).

Esta realidad estructural se concreta en espacios digitales masculinizados que, en su versión más antifeminista, conforman la denominada "manosfera" (manosphere). En la manosfera convergen diferentes grupos unidos por la aversión al feminismo y que desarrollan diferentes discursos para contrarrestar sus postulados (Ging, 2019; Almanzor, Pando y Congosto, 2020). Algunos de los sitios más relevantes de la subcultura trol, como 4chan o sectores de Reddit (Ging, 2019), alimentan esta manosfera, Sus discursos presentan el feminismo como tiránico contra los hombres y las mujeres no feministas (Almanzor, Pando y Congosto, 2020), además de centrar su crítica en figuras individuales, construidas simbólicamente como "villanas". Esta construcción simbólica permite las campañas posteriores de acoso y desprestigio que pueden acabar en ciberviolencia antifeminista. Se han utilizado diversos términos para definir este fenómeno: "odio online" (online hate), "e-bilis" (e-bile), "misoginia online" (online misogyny), "acoso en red" (networked harrasment) (Banet-Weiser y Miltner, 2016; Citron, 2014; Jane, 2014, Fairbairn, 2014). Siguiendo la lógica de la subcultural trolls, en este trabajo nos referiremos a estas acciones como gendertrolling. De este modo, según Mantilla (2013), el gendertrolling es una forma específica de violencia simbólica en entornos digitales, que se centra en el género y se dirige hacia las mujeres. A diferencia del LULZ de los trolls de 4chan, el gendertrolling se sustenta en una ideología antifeminista. Por ello, su agresividad será mayor hacia las mujeres que se autodefinen como feministas. En el ciber-imaginario feminista español se utiliza la expresión "machitrol" (Martínez-Jiménez y Zurbano-Berenguer, 2019). Como punto de partida, consideramos que el hashtag \#STOPfeminazis, difundido a través de la plataforma
Twitter, es representativo de estos espacios digitales antifeministas.

\section{Estudio de la subcultura troll a través de la etiqueta \#STOPfeminazis}

En este artículo, consideramos que, efectivamente, las desigualdades sociales y las formas de dominación existentes en el mundo offline tienen su traslación online, pero esta traslación está refractada por las propiedades específicas del submundo digital. La subcultura trol, como variante perversa de la cultura hacker, ilustra esta lógica cultural; emplea estrategias y métodos propios, basados en un estilo dialéctico confrontacional y una provocación emocional que puede acabar en la ciberviolencia. El análisis empírico realizado que presentamos en este apartado pretende contribuir a la comprensión del troleo antifeminista asociada a la subcultura troll a partir de un estudio de microdiscursos en Twitter.

No hay duda de que el activismo digital ha potenciado el feminismo, expandiendo y visibilizando los temas feministas en la esfera pública además de la autoreflexión sobre cuestiones de privilegio, diferencia y acceso (Rovira, 2018), pero también ha supuesto una fuerte reacción contraria desde plataformas, colectivos y usuarios individuales contrarios al feminismo que atacan fuertemente con ciberviolencia al movimiento feminista. La proliferación de la reacción antifeminista se ha evidenciado en las acciones de respuesta a campañas internacionales como \#MeToo o en el caso español \#Cuéntalo. El antifeminismo actual no siempre se envuelve de mensajes radicales o duros, sino que opera también en el terreno de la sutileza y no siempre es fácil de reconocer (Gutiérrez, Pando y Congosto, 2020).

La elección de esta etiqueta que ha circulado y circula por Twitter se debe a que fue una de las etiquetas más tuiteadas en las semanas anteriores al 8 de marzo de 2019 y por ello nos permite explorar las violencias simbólicas contra las mujeres a través del fenómeno conocido como gendertrolling (Mantilla, 2013). Las prácticas de troleo se relacionan de manera directa con la lógica machista normalizándose en el ciber-imaginario feminista español la expresión "machitrol" (MartínezJiménez y Zurbano-Berenguer, 2019).

Como Emma A. (2017) Jane afirma en Misogyny Online: a Short (and Brutish) History la misoginia es un fenómeno viral:

Resulta extremadamente revelador que la retórica de la violencia sexualizada y de género se haya vuelto tan común en línea. Y aunque internet no inventó el sexismo, lo está amplificando en formas sin precendentes (Jane, 2017, p. 3) .

De este modo, siguiendo la lógica trol, la etiqueta \#STOPfeminazis se caracteriza por la difusión de memes que tienden a ridiculizar y rebajar al adversario,

Traducción propia del original: "it is extremely revealing that the rhetoric of sexualised, gendered violence has become so common online. Yet while the internet did not invent sexism, it is amplifying it in unprecedented ways" (Jane, 2017, p. 3). 
pero también trata de perturbar el discurso feminista, presentado como dominante y amenazador, de acuerdo con una serie de oposiciones discursivas que refuerzan la mirada androcéntrica (Bourdieu, 2007). El objetivo es la desnaturalización del discurso feminista, siguiendo las tácticas de bricolaje y re-significación (Hebdige, 2004) propias del medio digital. De esta forma, se aspira a construir un contra-discurso que gane el combate dialéctico mediante golpes de efecto instantáneos (insultos y sarcasmos manifestados en forma de imágenes, memes y frases hechas).

\subsection{Selección dela muestra de análisis y consideraciones metodológicas}

Desde el punto de vista metodológico, la unidad de análisis es cada tuit seleccionado en la extracción realizada. La técnica de muestreo se delimita con un segmento temporal que incluye los tuits extraídos con el software utilizado desde el 1 de enero hasta el 14 de marzo de 2019. Este período ha sido elegido por tratarse de un tiempo amplio a las semanas previas a la celebración del 8 de marzo. La extracción de los tuits, un total de 295, algunos provenientes de cuentas identificable y otras anónimas; se realizó mediante el software cualitativo Atlas.ti 8, software de uso extendido en el análisis de datos cualitativos y que también permite la extracción de tuits en su última versión disponible (utilizamos la versión 8 en el momento de la extracción, aunque recientemente ha aparecido ya la 9).
La elección de la etiqueta central, \#STOPfeminazis, se debe a su viralidad e impacto en el período utilizado y su devenir como etiqueta de ofensiva en el espacio virtual, además de su contribución al gendertrolling o troleo machista, siguiendo la lógica subcultural que hemos comentado anteriormente

En referencia a las limitaciones metodológicas de este estudio cabe decir que no entramos a analizar las cuentas de las que proceden los tuits analizados, ni disponemos de variables sociodemográficas para ello. Hemos priorizado, por tanto, el análisis de los microdiscursos y la aplicación de la clasificación de categorías de ciberviolencia y troleo antifeminista.

\subsection{Metodología de análisis}

La investigación sobre el troleo de género o gendertrolling está proliferando en los últimos años con interesantes estudios que indagan sobre la caracterización de este fenómeno como variante misógina del troleo o trolling. Siguiendo a Karla Mantilla (2013) este troleo de género tiene varios componentes que lo distinguen del troleo como fenómeno en general. Esta autora afirma que el gendertrolling es especialmente destructivo para sus víctimas por una serie de características: los insultos basados en particularidades de género, lenguaje perverso, amenazas creíbles, la publicación de información personal o doxxing, ataques mucho más intensos y perpetuos y reacciones cuando las mujeres hablan o intervienen.

Tabla. 1. Categorías de análisis de las estrategias de troleo antifeminista mediante la etiqueta \#STOPfeminazis. Fuente: elaboración propia a partir de la adaptación de Crosas y Medina-Bravo (2019)

\begin{tabular}{|c|c|}
\hline Categoría de análisis & Definición \\
\hline Insulto & $\begin{array}{l}\text { El usuario/a usa un lenguaje ofensivo, abusivo y vulgar dirigido sistemáticamente a una } \\
\text { persona o grupos de personas. }\end{array}$ \\
\hline Sarcasmo & $\begin{array}{l}\text { El usuario/a expone un dicho irónico y cruel para ridiculizar, humillar o insultar a una } \\
\text { persona o grupos de personas. Apela al humor, pero de manera malintencionada y con el } \\
\text { objetivo de causar algún daño. }\end{array}$ \\
\hline Imposición & $\begin{array}{l}\text { El usuario/a ordena que se realice o deje de realizar una o varias acciones con el objetivo } \\
\text { de denigrar, estigmatizar o silenciar a una persona o grupos de personas. La oración } \\
\text { adquiere un tono imperativo o exclamativo. }\end{array}$ \\
\hline Deseo de dañar & $\begin{array}{l}\text { El usuario/a se centra en el deseo de provocar daño de manera explícita en otras personas. } \\
\text { Ejemplo: «Ojalá te mueras». También hace referencia a cuando el usuario/a quiere hacerse } \\
\text { daño a sí mismo con el objetivo de culpabilizar a una o varias personas. }\end{array}$ \\
\hline Objetivación sexual & $\begin{array}{l}\text { El usuario/a mira, trata y considera a una persona o grupos de personas como objetos } \\
\text { usados únicamente para el placer sexual (masculino). Su cuerpo en general o determinadas } \\
\text { partes del mismo se convierten en el tema central del comentario. }\end{array}$ \\
\hline $\begin{array}{l}\text { Criminalización y } \\
\text { difamación }\end{array}$ & $\begin{array}{l}\text { El usuario/a etiqueta a una persona o grupos de personas como criminales (por ejemplo, } \\
\text { como asesinos/a, violadores/a, etcétera) o difunde información falsa sobre determinados } \\
\text { sujetos (por ejemplo, con relación a su familia, pasado, etc.). }\end{array}$ \\
\hline $\begin{array}{l}\text { Amenaza a nivel } \\
\text { general }\end{array}$ & $\begin{array}{l}\text { El usuario/a realiza una declaración donde advierte de la intención de causar un dolor, } \\
\text { daño, perjuicio o cualquier otra acción hostil a una persona o grupos de personas. }\end{array}$ \\
\hline Amenaza sexual & $\begin{array}{l}\text { El usuario/a hace una declaración donde advierte de la intención de violentar sexualmente } \\
\text { a una persona o grupos de personas. }\end{array}$ \\
\hline $\begin{array}{l}\text { Ofensiva general al } \\
\text { movimiento feminista }\end{array}$ & $\begin{array}{l}\text { El usuario/a realiza una declaración de ataque al movimiento feminista y a las acciones } \\
\text { feministas en general, así como a la convocatoria del } 8 \text { de marzo. }\end{array}$ \\
\hline
\end{tabular}


Aunque consideramos que esta caracterización es muy aplicable para analizar el fenómeno del troleo de género a través de plataformas, y no descartamos hacerlo en un futuro, decidimos aplicar para este trabajo otra propuesta más reciente y detallada para estudiar las formas específicas de violencia digital y de troleo de las autoras Crosas y Medina-Bravo (2019) en la que analizan la violencia online contra las mujeres y antifeminista.

Por tanto, el análisis de los tuits seleccionados se ha llevado a cabo siguiendo la propuesta de Crosas y Medina-Bravo (2019), con una ligera adaptación en nuestro caso que ha supuesto añadir una nueva categoría. Este proceso permite mostrar resultados cuantitativos, porque se pueden contabilizar las palabras o categorías, así como un resultado cualitativo mediante la aplicación de un grupo de estrategias de misoginia digital consideradas como categorías de análisis de troleo antifeminista en su aplicación a la etiqueta seleccionada (tabla 1).

Siguiendo la propuesta de análisis de las autoras mencionadas, aplicada en un estudio de caso de comentarios principales en Youtube, lo aplicamos aquí para el caso de la red social Twitter con tuits que contienen la etiqueta \#STOPfeminazis, añadiendo una categoría más de análisis: ofensiva general al movimiento feminista.

\subsection{Resultados. El troleo antifeminista de \#STOPfeminazis}

La etiqueta seleccionada se acompaña de otras etiquetas frecuentes que dan un sentido u otro a la etiqueta central en nuestro análisis. Se trata de etiquetas como: \#ElFeminismoesCancer, \#IdeologíadeGénero o \#AbortaresDelitoNoDerecho, entre otras. Estas etiquetas secundarias o que acompañan matizan el sentido de la etiqueta principal porque también se observa la utilización de etiquetas como son \#DiadelaMujer o \#8M. La etiqueta \#8M es muy viral en el día de la celebración y días antes y después, e incluso durante todo el año, lo que nos lleva necesariamente a confirmar la necesidad de un análisis de contenido cualitativo para poder entender cómo dota de un sentido u otro a los tuits etiquetados.

Cabe apuntar que en este análisis no incorporamos la identificación de las apariciones y las impresiones que se utilizan para medir el grado de influencia de los micro-mensajes, como hemos realizado en un anterior trabajo sobre influyentes (Pecourt y Villar, 2018), sino que el objetivo es analizar cualitativamente la etiqueta \#STOPfeminazis en su uso para expandir la desinformación y contribuir al fenómeno gendertrolling.

En la muestra de tuits extraídos a partir de la etiqueta central para este análisis (\#STOPfeminazis) se pueden distinguir dos grupos de posicionamientos: los que se muestran contrarios al movimiento feminista y utilizan la etiqueta como forma de difundir el troleo antifeminista, empleando para ello las diferentes estrategias que podemos categorizar como antifeministas (de la muestra extraída son 234 tuits) y, por el contrario, aquellos mensajes que utilizan la etiqueta como una manera de defenderse de dichos ataques y contra acusaciones y campañas antifeministas (22 tuits). Además, hay varios tuits que no hemos clasificado en ninguno de los dos po- sicionamientos al ser meramente informativos o no ubicarse en ninguna posición, pero que incluyen la etiqueta (un total de 39 tuits).

En el intervalo temporal tenido en cuenta para este análisis y en la muestra extraída destaca que un total de 76 tuits se difundieron desde la cuenta de la organización HazteOir o la de su presidente en los que promueven una campaña que tiene como acción principal el recorrido de un autobús en algunas ciudades españolas bajo el lema "No es violencia de género, es violencia doméstica. \#StopFeminazis". Es precisamente esta campaña y la organización que la promueve la que ha contribuido a la viralización de la etiqueta y es utilizada tanto para anunciar las visitas o recorridos del autobús, como en actos privados de dicha organización.

En un mensaje de la propia organización HazteOir se promueve la etiqueta junto a un anuncio de un acto titulado “¿Cómo frenar el feminismo radical?”. La organización CitizenGO, vinculada a HazteOir, con sede en Madrid y con presencia en varios países definida como una comunidad de ciudadanos para defender la vida, la familia y la libertad, también difunde la etiqueta a través de su cuenta.

En este análisis hemos incorporado una nueva categoría como aportación propia a las categorías utilizadas por Crosas y Medina-Bravo (2019); esta nueva categoría la denominamos "ataque general al movimiento feminista". Añadimos esta categoría porque percibimos que en la selección de mensajes aparecen algunos de ellos formulados como contrarios al movimiento feminista mainstream. Esta categoría agruparía tuits que aluden a posiciones que afirman la existencia de igualdad entre hombres y mujeres y que niegan las reivindicaciones de la desigualdad estructural y la existencia del patriarcado. En uno de los tuits, por ejemplo, se pueden ver imágenes de manifestación con pancartas de la organización Women of the World, una plataforma que se define como una iniciativa que actúa frente a lo que denominan ideología de género, así como la misión de evitar que desde las instituciones y gobiernos se promulguen leyes que desprecien la identidad femenina, el valor y la dignidad de la maternidad o de la dedicación prioritaria a la familia.

Figura 1. Ejemplo de tuit de la categoría "ataque general al movimiento feminista". Fuente: elaboración propia a partirdela cuenta@iarsuaga

Manifestándome por la igualdad entre hombres y mujeres y contra la \#IdeologíaDeGenero en \#madrid \#8M \#StopFeminazis

La etiqueta también aparece en mensajes donde se hace mención explícita a personajes políticos pidiéndoles su actuación para derogar desde un sector antifeminista y negacionista la violencia de género, lo que denominan "las leyes de género". Se mencionan a líderes políticos como Pablo Casado (Partido Popular), Albert Rivera (Ciudadanos) y Santiago Abascal (Vox). De hecho, este trío político es el elegido a quien dirigir principalmente las peticiones de la campaña del autobús de 
la organización HazteOir. Esta organización apela a la actuación de estos políticos y sus partidos, utilizando su imagen y sus nombres, para derogar las que denominan "leyes de género" acusándolas de discriminatorias y totalitarias.

Figura 2. Ejemplo de tuit con mención explícita a políticos. Fuente: elaboración propia a partir de la cuenta@iarsuaga

Te recuerdo los motivos por los que @ hasteoir ha lanzado la campaña \#HOBus \#StopFeminazis coincidiendo con el \#8M para pedirles a Casado, Rivera y Abascal que deroguen las leyes (discriminatorias y totalitarias) de género

El troleo de género se refuerza con contenidos e imágenes propias de las fake news y cultura de la desinformación que han favorecido las redes sociales. De esta forma, los gatekeepers tradicionales (por ejemplo, la prensa de referencia) han perdido la capacidad de filtrar la información vertida en la esfera pública, al tiempo que han surgido actores anónimos que difunden alternative facts alejados de la contrastación empírica, pero que tienen un gran impacto emocional. La identificación de las fake news en la esfera digital y de su influencia en la creación de información y opinión resulta un tema de preocupación y de investigación clave en la actualidad (Cardon, 2020).

En este sentido, en una imagen de la organización HazteOir difundida junto a la etiqueta principal se recogen datos sobre el número de mujeres asesinadas por sus parejas con un gráfico de la evolución desde 1999 a 2005. El gráfico muestra que el número de asesinadas no desciende y por ello la organización afirma que "la Ley de Violencia de Género no funciona". Otro de los mensajes que acompañan la imagen es la afirmación de que "el 55\% de las mujeres afirma que la Ley de Violencia de Género no está ayudando a frenar la violencia contra las mujeres", dando a entender que la ley por sí misma debería suponer un freno a la violencia, que desde posiciones feministas se entiende como estructural al sistema. En otra imagen difundida en ese tuit y junto a la etiqueta de nuestro análisis se afirma que "Las actuales leyes contra la violencia de género sitúan al hombre en una posición de indefensión ante la mujer".

Hay varios medios de comunicación que aparecen vinculados a la etiqueta, como son Intereconomía o el programa El gato al agua, que difunden la campaña \#Stopfeminazis apelando al derecho de libertad de expresión.

El concepto feminazi se utiliza tanto como sustantivo como adjetivo que según el The Oxford Dictionary of American Political Slang: Se refiere despectivamente a "una feminista comprometida o a una mujer de voluntad fuerte" (p. 105). El término fue difundido y popularizado en Estados Unidos por el locutor de radio conservador Rush Limbaugh en el contexto del blacklash antifeminista de los años 80 y 90 para denigrar al movimiento feminista y las denominadas feministas radicales. Limbaugh (1992) define feminazi como "feministas radicales cuyo objetivo es ver tantos abortos como sea posible"'s.

En la muestra de tuits extraídos, "feminazismo" aparece definido a modo de comparativa junto al nazismo en una imagen difundida por HazteOir con la etiqueta \#Stopfeminazis. A juicio de los autores, atribuyendo supuestamente la autoría a la organización que firma el tuit, el nazismo y el feminazismo comparten, por ejemplo, la "incentivación y manipulación del odio", entre otras características.

Figura 3. ¿Feminismo o feminazismo? Fuente: elaboración propia a partir de la cuenta de la organización HazteOir@hazteoir.

\begin{tabular}{|l|l|}
\hline \multicolumn{2}{|c|}{ ¿FEMINISMO O FEMINAZISMO? } \\
\hline NAZISMO & FEMINAZISMO \\
\hline Supremacismo de la raza aria frente al resto. & Supremacismo de las mujeres frente a los hombres. \\
\hline $\begin{array}{l}\text { La nación alemana ha sido víctima y los judíos son los } \\
\text { culpables. }\end{array}$ & Las mujeres son víctimas. La culpa es de todos los hombres. \\
\hline Incentivación y manipulación del odio. & Incentivación y manipulación del odio. \\
\hline $\begin{array}{l}\text { Creación de leyes que vulneran derechos de una parte de la } \\
\text { población. }\end{array}$ & $\begin{array}{l}\text { Creación de leyes que vulneran derechos de una parte de la } \\
\text { población. }\end{array}$ \\
\hline Creación de delitos de autor y delitos colectivos. & Creación de delitos de autor y delitos colectivos. \\
\hline Persecución del disidente. & Persecución del disidente. \\
\hline Adoctrinamiento de los menores para implicarlos en el proyecto. & Adoctrinamiento de los menores para implicarlos en el proyecto. \\
\hline $\begin{array}{l}\text { Incentivación del chivato de disidentes con cierto poder (padres, } \\
\text { profesores....). }\end{array}$ & $\begin{array}{l}\text { Incentivación del chivato de disidentes con cierto poder (padres, } \\
\text { profesores...). }\end{array}$ \\
\hline Pensamiento totalitario que no admite críticas. & Pensamiento totalitario que no admite críticas. \\
\hline Imposición de ese pensamiento. & Imposición de ese pensamiento. \\
\hline $\begin{array}{l}\text { Utilización de técnicas de manipulación de masas para } \\
\text { implantar el pensamiento único. }\end{array}$ & $\begin{array}{l}\text { Utilización de técnicas de manipulación de masas para } \\
\text { implantar el pensamiento único. }\end{array}$ \\
\hline
\end{tabular}

Traducción propia del original: "here then is the definition and real agenda of the feminazi: radical feminists whose objective is to see that there are as many abortions as possible" (Limbaugh, 1992). 
Seguidamente, presentamos el análisis detallado por categorías de análisis en relación con las formas de troleo detectadas en la muestra de tuits que forma parte de este estudio sobre \#Stopfeminazis. En ellos se realiza una manipulación simbólica que utiliza las técnicas del remix y la instantaneidad propias de la cultura di- gital (manipulando lemas e imágenes), que favorece la viralidad instantánea sobre la sedimentación reflexiva. También sigue la lógica del hackeo del discurso racional pregonada por instancias trol como Encyclopedia Dramatica. Hemos realizado una selección de tuits, así como de aquellas categorías más destacadas.

Tabla. 2. Número de tuits clasificados por categorías. Fuente: elaboración propia

\begin{tabular}{|l|c|}
\hline \multicolumn{1}{|c|}{ Categorías de análisis } & Frecuencia \\
\hline Insulto & 22 \\
\hline Sarcasmo & 18 \\
\hline Imposición & 13 \\
\hline Deseo de dañar & 4 \\
\hline Objetivación sexual & 0 \\
\hline Criminalización y difamación & 29 \\
\hline Amenaza a nivel general & 5 \\
\hline Amenaza sexual & 0 \\
\hline Ataque general al movimiento feminista & 143 \\
\hline Feministas & 22 \\
\hline No clasificado & 39 \\
\hline Total & 295 \\
\hline
\end{tabular}

\section{a) Insulto}

El insulto es una estrategia de ciberviolencia frecuente. Se proclaman insultos al movimiento feminista como colectivo, especialmente dirigidos a las mujeres feministas, así como a hombres feministas que se suman al movimiento feminista dando apoyo a las mujeres que protagonizan las manifestaciones y acciones reivindicativas ("generación de idiotas sumisos, aliados feministas, vergüenza infinita"). También aparecen neologismos formados a partir de la palabra fémina que funcionan como insultos, es el caso de "femipatéticas" o "feminecias".

Se difunden insultos a personas concretas de manera nominal. En ocasiones se trata de insultos que utilizan términos propios de la cultura digital como "banda de trolls feminazis" atacando así a las personas que protestaban en Valencia para detener el autobús de HazteOir y mencionando al alcalde y la vicealcaldesa como responsables.

Figura 4. Ejemplo de tuit de la categoría Insulto. Fuente: cuenta de@iarsuaga

Hoy una banda de Trolls \#Feminazis de \#Valencia ha insultado y agredido a los portavoces del \#HOBus Este nivel de odio roza lo diabólico Los resposanbles: @ joanribo@SanGomezLopez y sus grupos políticos que han señalado al disidente Hoy más que nunca \#StopFeminazis

\section{b) Sarcasmo}

Otra categoría frecuente utilizada por el troleo antifeminista es el sarcasmo. Entre la multitud de memes e imágenes que acompañan los tuits, por ejemplo, apare- ce varias veces en la muestra seleccionada una foto de una mujer con un cartel que dice "No quiero tu piropo, quiero que te mueras". En la imagen han añadido un fotomontaje con un mensaje de un hombre con otro cartel que dice "Prefiero morir". Este tipo de mensajes sarcásticos son frecuentes en la subcultura trol.

Una cuenta que parodia a HazteOir que se denomina Hástelo Mirar incluye un meme parodiando a la organización Women of the World en una manifestación. En otro tuit aparece el mensaje de incluir al bus de HazteOir en la película de animación dirigida al público infantil Cars.

El sarcasmo se observa en una ilustración donde se compara el perfil de un obrero ("currando desde los 15") con una feminista ("en Twitter desde los 15") aludiendo a la vida de esfuerzo del obrero frente a la "buena vida" de la feminista.

También se difunden mensajes en clave sarcástica que apuntan a la comparación entre el feminismo y el nazismo, una conexión vinculada de manera directa con la etiqueta analizada.

Desde cuentas concretas se propagan mensajes sarcásticos, como es el caso de la cuenta denominada $\mathrm{Pa}$ blito Perroflauta (en referencia al político Pablo Iglesias de Podemos) donde se utiliza la etiqueta central de este análisis acompañada de expresiones en clave sarcástica y otras etiquetas (\#azotarhastasangrar, \#NoHablesEnMiNombre, por ejemplo).

\section{c) Imposición}

La imposición también es una categoría que puede ser empleada para analizar el contenido de troleo de género. La imposición en un sentido de atacar al movimiento feminista porque "impone" sus leyes de género según estos ataques antifeministas. La etiqueta es utilizada para reclamar que el $8 \mathrm{M}$ y la huelga feminista es considerada 
una "imposición de género" por sectores ideológicos contrarios. Por ejemplo, una representante política de Vox considera que es una imposición la convocatoria de huelga de mujeres para el $8 \mathrm{M}$.

Figura 5. Ejemplo de tuit de la categoría Imposición. Fuente: tuit de la cuenta de@Sussuarez

Día de trabajo como cualquier otro. No creo que por ser \#mujer tenga que celebrar nada. Es la mayor discriminación que se me puede hacer. En contra de imposiciones de género y del adoctrinamiento contra el hombre. \#8M \#8M2019 \#NoHablesEnMiNombre \#STOPFeminazis

Posicionamientos contrarios al movimiento feminista y a la convocatoria del $8 \mathrm{M}$ que son defendidos como una imposición recibida por ese movimiento en nombre de la libertad de expresión.

El discurso excluyente se apropia de las consignas y lemas de ideologías contrapuestas, siguiendo la lógica del bricolaje analizada por Hebdige (2004), como es el caso de un tuit donde se difunde este lema: "Feminazis fuera de nuestros barrios" que recuerda a un conocido lema antifascista: "Fascistas fuera de nuestros barrios".

Aparece una parodia de la conocida novela de Margaret Atwood y popular serie de televisión El cuento de la criada con una imagen de un disfraz versión sexualizada junto a la declaración de "femipatéticas".

La etiqueta central del análisis se acompaña de otras etiquetas frecuentes en este tipo de campañas propias del movimiento antigénero y antifeminista, como es la etiqueta \#IdeologíaDeGénero.

La acusación al movimiento feminista de "ideólogas de género" junto a imágenes de mujeres que sostienen carteles con mensajes como "Soy mujer y este 8M trabajaré por todas las que ya lucharon por mi independencia y libertad". Un tipo de discurso con lemas y conceptos que suelen aparecer también en campañas feministas mainstream ("luchar", "independencia", "libertad") y que son reapropiadas justamente para atacar al movimiento feminista en la convocatoria del $8 \mathrm{M}$. Sin duda, se constata aquí el fenómeno de la reapropiación de los lemas y consignas, e incluso simbología, de un movimiento para contrariamente atacarlo.

\section{d) Deseo de dañar}

Otra categoría frecuente en los mensajes de troleo o ciberviolencia es la intención o deseo de dañar. La etiqueta central analizada se acompaña de otras etiquetas, como es la etiqueta \#Elfeminismoescáncer en varias ocasiones o \#azotarhastasangrar que suponen la intencionalidad clara de dañar. Los comentarios que se añaden pretenden dañar al movimiento feminista y a la convocatoria reivindicativa del 8 de marzo. Se encuentran contenidos relacionados con el deseo de dañar refiriéndose a la temática del aborto (“¿Por qué tu madre no te abortó?”); un posicionamiento antiabortivo que justifica incluso la utilización de la imagen de Hitler en la campaña del autobús de HazteOir.

Figura 6. Ejemplo de tuit de la categoría Deseo de dañar. Fuente: cuenta de@hazteoir

Estamos en un país donde las feministas radicales que se manifiestan el \#8M pueden decir "os ahogaréis con la sangre de nuestros abortos" y nosotros no podemos sacar una creatividad de Hitler con un símbolo feminista radical" \#STOPFeminazis

Figura 7. Imagen del autobús de la campaña de HazteOir con la imagen de Hitler customizado junto a la etiqueta \#StopFeminazis. Fuente: imagen de la cuenta @bushazteoir

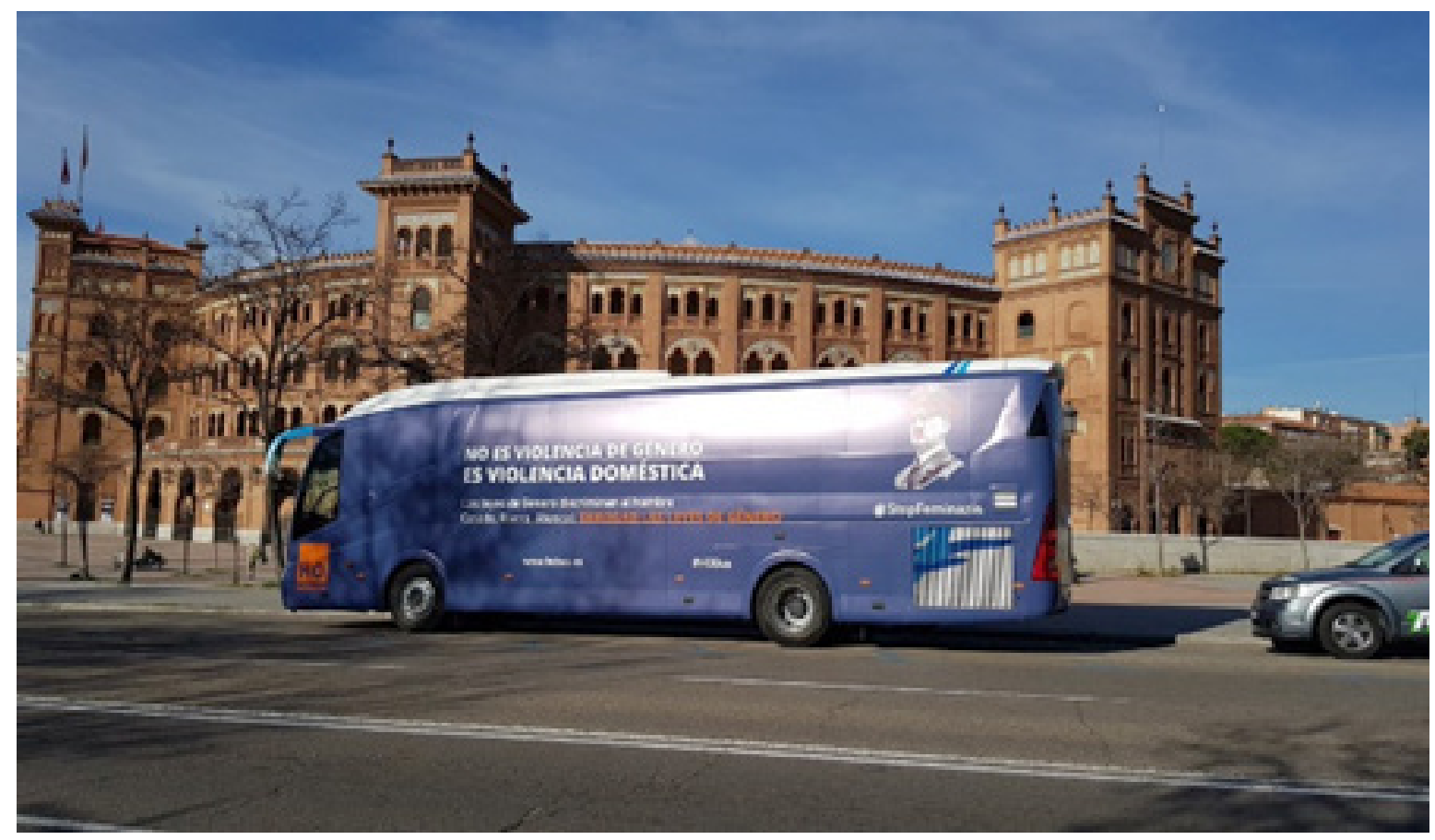




\section{e) Criminalización y difamación}

La referencia a las denuncias falsas de violencia de género es uno de los contenidos vinculados a la categoría de criminalización o difamación. En este sentido, un colectivo denominado Asociación Projusticia que organizan actos con el lema "Stop Feminazis" como lema central en sus pancartas y otros como "Para maltrato el de los padres separados" difunden tuits en este sentido difamatorio cuestionando las denuncias por violencia de género. Concretamente, en su página web puede leerse que "al igual que el nazismo, el feminazismo utiliza el victimismo apoyándose en mentiras y datos falsos".

Figura 8. Ejemplo de tuit de la categoría Criminalización y difamación. Fuente: tuit de la cuenta de la Asociación Projusticia@ProjusticiaInfo

La industria del maltrato da cobijo a miles de estómagos agradecidos. No es de extrañar que todas estas parásitas pongan el grito en el cielo cuando ven peligrar sus chiringuitos mantenidos con el dinero de los contribuyentes \#STOPFeminazis

Otro ejemplo de difamación es la acusación del trato que recibió el autobús de HazteOir en Valencia tratado como sujeto, subjetivizado, que está siendo violentado y perseguido ("desvinilado", en referencia al hecho que le quitaron el vinilo del Hitler customizado para hacer cumplir una ordenanza municipal), junto a la acusación explícita al alcalde de delito de prevaricación y de vulneración de derechos democráticos por no permitir que recorra las calles de la ciudad.

\section{f) Ataque general al movimiento feminista}

En última instancia comentaremos la categoría que hemos incorporado denominada "ataque general al movimiento feminista". Esta categoría de análisis complementa las otras categorías porque se identifican mensajes con un ataque general al movimiento feminista, y no tanto a personas individuales o asuntos concretos, sino una ofensiva de tipo colectivo. Esta reacción aparece de manera frecuente y puede tener relación como reacción a éxitos de convocatoria y movilización del movimiento feminista tras la cita del 8 de marzo de 2018 considerada como primera huelga general feminista realizada en España. La reacción en forma de troleo a este éxito de movilización se aprecia en mensajes de ciberviolencia a modo de sinécdoque, tomando como sujeto de ataque a la totalidad del movimiento siendo internamente muy diverso.

El movimiento feminista es acusado de crear un enfrentamiento entre hombres y mujeres. También aparecen referencias más concretas a colectivos como Femen mostrando fotografías de un grupo de activistas de esa organización en una iglesia descontextualizada al mensaje del tuit que da apoyo a Vox Castellón. La utilización de imágenes descontextualizadas es propia de la cultura del engaño o fake news.
Dentro de esta categoría se pueden ubicar mensajes contra lo que denominan "las leyes de género", en referencia a la Ley contra la Violencia de Género y la Ley de Igualdad, justificándolo como discriminatorias contra el hombre.

Por último, hay que comentar que en algunas ocasiones los mensajes que incorporan la etiqueta \#STOPfeminazis no expresan ninguna manifestación de amenaza concreta porque la etiqueta acompaña la campaña del autobús, pero sí que puede entenderse como de apoyo a la difusión de dicha campaña y tipo de discurso antifeminista. Este tipo de mensajes suelen también aparecer acompañados de otras etiquetas cómo \#8MNoMeRepresenta o \#feminazismo que expresa la sustantivación derivada de "feminazi" otorgándole la dimensión de movimiento o ideología ("el feminazismo").

En definitiva, \#STOPfeminazis se presenta como un antídoto al discurso feminista que los participantes consideran hegemónico en la sociedad española. Más concretamente se dirige a dos variantes específicas: a) el "feminismo institucional" (o "feminismo de Estado" según Long (2013)), es decir, el feminismo inscrito en las instituciones públicas, con fuerza para influir en las políticas públicas y que personalizan en figuras como Carmen Calvo (actual vicepresidenta primera del Gobierno) o Irene Montero (actual ministra de igualdad); y b) el "feminismo mediático" que se expresa tanto en la prensa diaria como en las redes sociales y que tiene una gran influencia para moldear la opinión pública y construir una determinada imagen del mismo, a través de influencers feministas. \#STOPfeminazis pretende difundir una determinada visión de la sociedad: contrapone una sociedad orgánica y cohesionada, centrada en el orden y los valores tradicionales, con una sociedad artificial y conflictiva, caracterizada por la guerra de sexos (que reproduce la antigua lucha de clases) entre hombres y mujeres. En términos generales, este ejercicio de remezcla pretende desplazar discursivamente al feminismo de la esfera pública presentándolo como perjudicial para los intereses de los hombres y, también, del conjunto de la sociedad.

\section{Discusión y conclusiones}

Los resultados de este estudio sobre el troleo de género en Twitter muestran que los ataques al movimiento feminista, tanto en un sentido colectivo, como referido a personalidades individuales, son frecuentes en el entorno digital. A diferencia de los medios de comunicación de masas tradicionales, Twitter es un espacio comunicativo abierto en el que participan múltiples actores, y en el que los individuos pueden manifestarse de forma anónima. Esta plataforma facilita la polarización y la discusión agonística, una tendencia que se remonta a los orígenes de Internet. El carácter intimidatorio que pueden tener las conversaciones en Twitter se asocia con el androcentrismo de la cultura digital desde sus orígenes, y que ha ido evolucionando desde la exclusión inicial de las mujeres hasta las actuales formas de gendertrolling. 
El análisis de la etiqueta central utilizada en este estudio, \#STOPfeminazis, se ha realizado en las semanas anteriores a la celebración del 8 de marzo de 2019. Como muestran los datos y resultados expuestos, se trata de un hashtag difundido principalmente desde cuentas vinculadas y afines a una campaña protagonizada por la organización HazteOir. Dicha etiqueta aparece en múltiples mensajes que manipulan y resignifican postulados del movimiento feminista. Además, esta etiqueta principal se acompaña de etiquetas secundarias que matizan a la principal, es decir, que pueden intensificar el mensaje antifeminista o, por el contrario, presentar un mensaje feminista, que utiliza ese hashtag para cuestionar y resistir los ataques al feminismo. Además del antifeminismo, la etiqueta muestra una exaltación de los discursos que apelan al nacionalismo español, a la simbología de tipo españolista junto a la simbología relacionada como propia, como es la bandera de España y las fuerzas de seguridad del Estado. También se observa discurso católico y promoción de valores conservadores atribuyendo al feminismo una idea de guerra entre sexos. En la expansión de la etiqueta tienen un protagonismo importante personas o cuentas vinculadas al partido político Vox. En muchos casos, el ataque al feminismo se enmarca en un ataque más general a las posiciones políticas de izquierdas.

Podría decirse que del análisis de contenido de \#STOPfeminazis en Twitter emerge una cultura del engaño y fake news, apreciándose en la expansión de los mensajes de troleo antifeminista. Esta corriente de desinformación, facilitada por el anonimato de los usuarios, supone una presentación distorsionada de los datos; de este modo, se da más importancia al impacto emocional de los mensajes (y a su capacidad de movilización político-social) que a la presentación veraz y objetiva de la información, tal como prescribe el código deontológico de los profesionales de la información (Cardon, 2020). Al entender la desinformación como un instrumento de la confrontación políti- ca, no es extraño que este instrumento se utilice, también, contra el movimiento feminista.

El caso de \#STOPfeminazis muestra que el movimiento feminista está en el punto de mira de la subcultura trol en Twitter. Esta campaña de acoso y desprestigio surge desde una densa red de microdiscursos, donde se diseminan diversas formas de ciberviolencia. Así, en las últimas convocatorias del 8 de marzo, han aumentado las campañas de acoso contra el movimiento feminista, algo que podría relacionarse con las siguientes razones: a) la mayor presencia en las redes digitales del feminismo y del activismo digital de las mujeres, lo que conlleva una reacción contra el aumento de la presencia feminista en el espacio digital; b) una respuesta al éxito de convocatoria del movimiento feminista, especialmente, desde el 2018, por parte de personas o grupos contrarios a estos avances; c) la propagación del troleo de género como una respuesta organizada de partidos políticos vinculados a la extrema derecha y organizaciones ultracatólicas, como se observa en el análisis de \#STOPfeminazis.

Observamos que la propagación del troleo de género está expandiéndose y penetrando en la arena política y en los discursos de representantes políticos, incluso en los ámbitos más formales del parlamentarismo. Se trata de una hipótesis que podría ser explorada en un futuro.

El estudio expuesto no supone un caso aislado de troleo antifeminista, sino que se vincula a una corriente de misoginia en red conectada con un movimiento antifeminista y antigénero internacional impulsado a través de organizaciones y partidos políticos de ideología de extrema derecha encargados de extender y amplificar este tipo de ataques. En la última convocatoria del 8 de marzo de 2020 se ha vuelto a evidenciar el ataque organizado al movimiento feminista e, incluso, la culpabilización de la expansión de la pandemia del coronavirus. Estos hechos sugieren una interesante línea de investigación futura para seguir profundizando en el troleo antifeminista como fenómeno social.

\section{Referencias}

Banet-Weiser, S. y Miltner, K. (2016). \#MasculinitySoFragile: culture, structure, and networked misogyny. Feminist Media Studies, 16(1), 171-174, https://doi.org/10.1080/14680777.2016.1120490

Bardeau, F. y Danet, N. (2011). Anonymous. Pirates informatiques ou altermondialistes. París: FYP Editions.

Benkler, Y. (2006). The wealth of networks. How social production transforms markets and freedom. New Haven: Yale University Press.

Bourdieu, P. (2007). La dominación masculina. Barcelona. Anagrama.

Boyd, D. y Crawford, K. (2012). Critical questions for big data. Provocations for a cultural, technological, and scholarly phenomenon. Information, Communication, and Society, 15(5), 662-679. https://doi.org/10.1080/1369118X.2012.678878

Cardon, D. (2020). Culture numérique. Paris: SciencesPo.

Citron, D. (2014). Hate crimes in cyberspace. Cambridge (MA): Harvard University Press.

Coleman, G. (2012). Phreaks, hackers and trolls: the politics of transgression and spectacle. En (Mandiberg, M., eds.) The social media reader. Nueva York: New York University Press.

Coleman, G. (2016). Las mil caras de Anonymous. Hackers, activistas, espías y bromistas. Barcelona: Arpa y Alfil Editores.

Crosas, I. y Medina-Bravo, P. (2019). Ciberviolencia en la red. Nuevas formas de retórica disciplinaria en contra del feminismo. Papers, 104(1), 47-73. http://dx.doi.org/10.5565/rev/papers.2390

DiFranco, R. (2020). I Wrote this Paper for the Lulz: The Ethics of Internet Trolling. Ethical Theory and Moral Practice, 23, 931-945. https://doi.org/10.1007/s10677-020-10115-x

Fairbairn, J. (2015). Rape threatws and revenge porn: defining sexual violence in the digital age. En (eds. Bailey, J. y Steeves, V.) EGirls, Ecitizens Ottawa: University of Ottawa Press.

Fraser, N. (1992). Rethinking the public sphere: a contribution to the critique of actually existing democracy. En (Calhoun, C. eds) Habermas and the public sphere. Cambridge (MA): The MIT Press. 
Gere, C. (2008). Digital Culture. Londres: Reaktion Books.

Ging, D. (2019). Alphas, Betas and Incels: theorizing the masculinities of the manosphere. Men and Masculinities, 22(4), 638657. https://doi.org/10.1177/1097184X17706401

Ging, D. y Siapera, E. (2018). Special issue on online misogyny. Feminist Media Studies, 18(4), 515-524. https://doi.org/10.108 $0 / 14680777.2018 .1447345$

Ging, D. and Siapera, E. (2019). Gender Hate Online: Understanding the New Anti-Feminism. London: Palgrave Macmillan.

Gutiérrez Almazor, M., Pando Canteli, M. y Congosto, M. (2020). Nuevos enfoques en la propagación de la reacción antifeminista en Twitter. Investigaciones Feministas, 11(2), 221-237. https://doi.org/10.5209/infe.66089

Habermas, J. (1981). Historia y crítica de la opinión pública: la transformación estructural de la vida pública. Barcelona: Gustavo Gili.

Hafner, K. y Lyon, M. (1996). Where Wizards Stay Up Late: The Origins Of The Internet. Nueva York: Simon and Schuster.

Hebdige, D. (1979). Subculture. The meaning of style. Londres: Routledge

Hebdige, D. (2004). Subcultura. El significado del estilo. Barcelona: Paidós.

Heikkilä, N. (2017). Online antagonism of the alt-right in the 2016 Election. European Journal of American Studies. 12(2), document 5, Online since 02 August 2017, connection on 26 November 2020. https://doi.org/10.4000/ejas.12140

Jane, E. A. (2014). "You're a Ugly, Whorish, Slut" Understanding e-bile. Feminist Media Studies, 14(4), 531-546. https://doi.or $\mathrm{g} / 10.1080 / 14680777.2012 .741073$

Jane, E. A. (2017). Misogyny Online: A Short (and British) History. Londres: Sage.

Jacobs, R. y Townsley, E. (2011). The space of opinion: media intellectuals and the public sphere. Oxford: Oxford University Press.

Kendall, L. (2002). Hanging out in the virtual pub. Masculinities and relationships online. Berkeley (CA): University of California Press.

Lanier, J. (2011). You are not a gadge. Londres: Penguin.

Lessig, L. (2012). Remix. Cultura de la remezcla y derechos de autor en el entorno digital. Barcelona: Icaria.

Levmore, S. y Nussbaum, M. (eds.) (2010). The Offensive Internet: Speech, Privacy and Reputation. Cambridge (MA): Harvard University Press.

Levy, S. ([1984] 2010) Hackers. Heroes of the Computer Revolution. Sebastopol (CA): O’Reilly Media.

Limbaugh, R. (1992). Way Things Ought to Be. Nueva York: Pocket Books.

Lumsden, K. y Morgan, H. (2017). Media framing of trolling and online abuse: silencing strategies, symbolic violence, and victim blaming. Feminist Media Studies, 17(6), 926-940. https://doi.org/10.1080/14680777.2017.1316755

Mantilla, K. (2013). Gendertrolling: Misogyny Adapts to New Media. Feminist Studies, 39(2), 563-570. https://www.jstor.org/ stable/23719068

Martínez-Jiménez, L. y Zurbano-Berenguer, B. (2019). Posmachismo, violencia de género y dinámicas de opinión en los cibermedios. Aproximaciones a la realidad española a partir de la experiencia de eldiario.es. Teknokultura. Revista de Cultura Digital y Movimientos Sociales, 16(2), 213-228. https://doi.org/10.5209/tekn.65173

Marwick, A. (2013). Status update. Celebrity, publicity, and branding in the social media age. New Haven: Yale University Press.

Milan, S. y Gutiérrez, M. (2015). Medios ciudadanos y big data. La emergencia del activismo de datos. Mediaciones, 11(14), 1026. https://doi.org/10.26620/uniminuto.mediaciones.11.14.2015.10-26

Milner, R. (2014). Hacking the social: Internet memes, identity antagonism, and the logic of LULZ. Fibreculture Journal. Recuperado de: https://fibreculturejournal.org/wp-content/pdfs/FCJ-156Ryan\%20Milner.pdf

Nagle, A. (2017). Kill All Normies: Online Culture Wars From 4Chan and Tumblr To Trump and The Alt-Right, Londres: Zero Books.

Nussbaum, M. (2010). Objectivation and Internet misogigy. En S. Levmore y M. Nussbaum (eds.). The offensive Internet: speech, privacy and reputation. Cambridge (MA): Harvard University Press.

Pecourt Gracia, J. (2015). La esfera pública digital y el activismo político. Política y Sociedad, 52(1), 75-98. https://doi. org/10.5209/rev POSO.2015.v1.n52.45423

Pecourt Gracia, J. y Villar-Aguilés, A. (2018). Orígenes de las movilizaciones \#primaveravalenciana. Un análisis de los actores sociales más influyentes en Twitter. Athenea Digital, 18(2), 18-57. https://doi.org/10.5565/rev/athenea.1857

Phillips, W. (2015). This Is Why We Can't Have Nice Things. Cambridge: MIT.

Rovira Sancho, G. (2018). El devenir feminista de la acción colectiva: las redes digitales y la política de prefiguración de las multitudes conectadas. Teknokultura. Revista de Cultura Digital y Movimientos Sociales, 15(2), 223-240. https://doi. org/10.5209/TEKN.59367

Sandoval, G. (2013). The end of kindness: Weev and the cult of the angry young man. Recuperado de: https://www.theverge. com/2013/9/12/4693710/the-end-of-kindness-weev-and-the-cult-of-the-angry-young-man

Schopenhauer, A. (2011). El arte del insulto. Madrid: Alianza Editorial.

Shifman, L. (2014). Memes in the Digital Culture. Cambridge (MA): The MIT Press.

Shirky, C. (2008). Here Comes Everybody. Nueva York: Penguin.

Srnizek, N. (2016). Platform Capitalism. Cambridge: Polity Press.

Striker, C. (2011). Epic win for Anonymous. How 4chan's army conquered the world. Nueva York: Overlook.

Swallow, P. y Hall, E. (2020). Aristophanic Humour. Theory and Practice. Londres: Bloomsbury.

Wessler, H. (2018). Habermas and the Media. Cambridge: Polity Press. 